\title{
ANALISIS PERENCANAAN PAJAK DALAM PERHITUNGAN PAJAK PENGHASILAN BADAN PADA PT. SINAR CIPTA PERSADA SEJATI
}

\author{
Blandina Sefrida Kenju ${ }^{1}$, Inggriani Elim² ${ }^{2}$ Rudy J Pusung ${ }^{3}$ \\ 1,2,3 Jurusan Akuntansi, Fakultas Ekonomi dan Bisnis, Universitas Sam Ratulangi, Jl. Kampus Bahu, Manado, \\ 95115, Indonesia \\ E-mail : blandinakenju@gmail.com
}

\begin{abstract}
The purpose of this study was to determine the application of tax planning in calculation the corporate income tax owed at PT. Sinar Cipta Persada Sejati. The results of this study are expected to be able to provide information and input to the company PT. Sinar Cipta Persada Sejati so that companies can carry out tax planning in an effort to calculation tax payments, but still in income tax legislation No. 36 of 2008. With the implementation of tax planning by the company, it can calculation the burden of corporate tax payable as much as Rp. 2,500,000.
\end{abstract}

Keywords: Tax planning; corporate income tax

\section{PENDAHULUAN}

Tujuan perencanaan pajak bukanlah untuk menghindari pembayaran pajak, tetapi merancang atau mengatur agar pajak yang dibayarkan tidak lebih dari yang seharusnya. Sehingga dapat kita ketahui tujuan pokok perencanaan pajak adalah untuk mengurangi jumlah atau total pajak yang harus di bayarkan oleh wajib pajak yang merupakan tindakan legal karena penghematan pajak hanya dilakukan dengan memanfaatkan hal-hal yang diatur oleh undang-undang perpajakan sehingga menjadi langkah yang tepat dalam meminimalisir pembayaran beban pajak penghasilan badan. PT. Sinar Cipta Persada Sejati menginginkan laba yang optimal. Namun selain laba yang maksimal manajemen perusahaan menginginkan agar pajak penghasilan yang dibayar juga dapat diminimalisir sesuai dengan peraturan yang berlaku saat ini. Maka perusahaan melakukan perencanaan pajak dengan cara yang legal dan sesuai dengan UU No. 36 tahun 2008.

\section{TINJAUAN PUSTAKA}

Konsep Akuntansi. Menurut (Bahri 2016:2) Akuntansi adalah seni pencatatan, penggolongan, pengikhtisaran, dan pelaporan atas suatu transaksi dengan cara sedemikian rupa, sistematis dari segi isi dan berdasarkan standar yang diakui umum. Menurut Rafael Ga (2017:1) Akuntansi artinya laporan, catatan, rekening, harga, nilai, perhitungan. Akuntansi memiliki pengertian seni pencatatan, pengikhtisaran, dan pelaporan transaksi sehingga menjadi laporan keuangan yang digunakan oleh pihak tertentu untuk pengambilan keputusankeputusan bisnis.

Akuntansi Pajak. Menurut Estralita (2013:10) Akuntansi pajak adalah menetapkan besarnya pajak terutang berdasarkan laporan keuangan yang disusun oleh perusahaan. Menurut Gunadi (2013:9) pajak adalah suatu pungutan yang berupa hak preogratif pemerintah, pungutan tersebut didasarkan pada Undang - Undang, pemungutannya dapat dipaksakan kepada subjek pajak untuk mana tidak ada balas jasa yang langsung dapat ditunjukkan penggunaannya. Menurut Mardiasmo (2016:1) Pajak adalah iuran rakyat kepada kas negara berdasarkan undang-undang (yang dapat dilaksanakan) dengan tiada mendapat jasa timbal (kontraprestasi) yang langsung dapat ditunjukkan dan yang digunakan untuk membayar pengeluaran umum. Menurut Undang-Undang No.28 Tahun 2007 tentang 
Ketentuan Umum dan Tata Cara Perpajakan Pasal 1 "Pajak adalah kontribusi wajib kepada negara yang terutang oleh pribadi atau badan yang bersifat memaksa berdasarkan Undangundang, dengan tidak mendapatkan imbalan secara langsung dan digunakan untuk keperluan negara bagi sebesar-besarnya kemakmuran rakyat".

Pajak Penghasilan. Menurut Resmi (2014:74) Pajak Penghasilan (PPh) adalah pajak yang dikenakan terhadap subjek pajak atas penghasilan yang diterima atau diperolehnya dalam suatu tahun pajak.

Perencanaan Pajak. Menurut Pohan (2013) perencanaan pajak adalah suatu alat dan suatu tahap awal dari manajemen perpajakan yang berfungsi untuk menampung aspirasi yang berkembang dari sifat dasar manusia itu.

Pajak Penghasilan Badan. Berdasarkan Undang-Undang Pajak Nomor 36 Tahun 2008 salah satu yang menjadi subjek pajak adalah badan. Dalam menghitung Pajak Penghasilan yang terutang, dibedakan antara Wajib Pajak dalam negeri dan Wajib Pajak luar negeri. Tarif pajak untuk Wajib Pajak badan dalam negeri dan bentuk usaha tetap (BUT) sebesar 28\% (dua puluh delapan persen). Tarif PPh tersebut menjadi 25\% (dua puluh lima persen) mulai berlaku tahun pajak 2010.

Penelitian Terdahulu. Cynthia, (2017) menunjukkan bahwa perencanaan pajak dapat menurunkan besarnya pajak terutang akhir tahun perusahaan sebesar Rp 23.906.427 atau sebesar 57,59\%. Efendi, (2014) menemukan bahwa wajib pajak badan (perusahaan perbankan) yang melakukan perencanaan pajak sebesar 60,87\%, sisanya 39,13\% masih belum melakukan perencanaan pajak, persentase wajib pajak badan (perusahaan perbankan) yang melakukan perencanaan pajaknya secara efisien sebesar 82,14\%. Kawor, (2014) bahwa menunjukkan perusahaan dalam kegiatan perencanaan pajak mempertahankan tarif pajak penghasilan badan yang rendah. Sitohang, (2017) menunjukan perencanaan pajak (tax planning) $\mathrm{PPh}$ pasal 21 mampu mengefisienkan pajak penghasilan perusahaan tahun 2013 sebesar Rp10.541.000, tahun 2014 sebesar Rp 21.355.750 dan tahun 2015 sebesar Rp 24.474.000. Setyaningrum (2016) menunjukkan bahwa variabel operasi asing dan arus kas sebelum pajak dari variabel operasi berpengaruh positif terhadap ABTD. Sedangkan ukuran variabel perusahaan berpengaruh negatif terhadap ABTD.

\section{METODE PENELITIAN}

Jenis penelitian. Penelitian ini menggunakan jenis penelitian kualitatif dengan menggunakan analisis deskriptif. Jenis penelitian ini bermaksud untuk memahami fenomena tentang apa yang dialami oleh subjek penelitian secara umum dan di jelaskan dengan deskripsi dalam bentuk kata-kata dan bahasa, pada suatu konteks khusus yang alamiah dan memanfaatkan berbagai sumber metode ilmiah.

Jenis, sumber, dan metode pengumpulan data. Penelitian ini menggunakan data kualitatif yaitu data yang diperoleh dari wawancara tentang profil perusahaan dan data kuantitatif seperti laporan keuangan perusahaan. Sumber berupa hasil wawancara dengan direktur dan staf bagian akuntansi, sedangkan metode pengumpulan data yang digunakan berupa wawancara, dokumentasi, dan studi kepustakaan.

Metode dan proses analisis. Metode analisis yang digunakan dalam penelitian ini adalah metode analisis deskriptif. Adapun proses-proses analisis yang dilakukan dalam penelitian ini, yaitu: (1) tahap pertama, melakukan wawancara yang berhubungan dalam penulisan ini; (2) tahap kedua, peneliti mengumpulkan data dan mencatat semua data sesuai mengenai kebijakan, serta prosedur-prosedur yang dijalankan perusahaan; (3) tahap ketiga, melakukan analisis data yang telah di peroleh untuk mengetahui apakah perencanaan pajak dapat meminimalisir pajak penghasilan badan pada PT. Sinar Cipta Persada Sejati atau telah dijalankan dengan baik dan sesuai dengan aturan-aturan yang berlaku di perusahaan; dan (4) tahap keempat, pemberian kesimpulan dan saran. Pemberian kesimpulan diambil dari hasil 
wawancara dan penyajian data dan memberikan saran kepada perusahaan apa yang harus dilakukan atau diperhatikan kedepannya.

\section{HASIL PENELITIAN DAN PEMBAHASAN}

\subsection{Hasil Penelitian}

Berikut ini laporan Laba Rugi Tahun 2017 PT. Sinar Cipta Persada Sejati sebelum melaksanakan kebijakan perencanaan pajak yang disajikan dalam tabel 1.

Tabel 1. Laporan laba rugi per 31 Desember 2017

\begin{tabular}{|c|c|c|}
\hline Uraian & Satuan (Rp) & Jumlah \\
\hline Pendapatan Jasa Proyek & $\mathrm{Rp}$. & 3.341 .879 .914 \\
\hline \multicolumn{3}{|l|}{ Harga Pokok Proyek: } \\
\hline Pembelian/Pemakaian Bahan dan Material & Rp. & 1.010 .322 .939 \\
\hline Upah Proyek & Rp. & 556.757 .968 \\
\hline Biaya Angkut Bahan/Material Proyek & Rp. & 98.441 .739 \\
\hline Biaya Operasional Proyek & Rp. & 114.265 .000 \\
\hline Biaya Penyusutan Peralatan Proyek & Rp. & 1.209 .659 .785 \\
\hline Biaya Proyek Lainnya & $\mathrm{Rp}$. & 12.500 .000 \\
\hline Harga Pokok Proyek & Rp. & 3.001 .947 .431 \\
\hline Laba Kotor & Rp. & 339.932.483 \\
\hline \multicolumn{3}{|l|}{ Biaya Usaha } \\
\hline Biaya Gaji Karyawan Kantor & Rp. & 234.000 .000 \\
\hline Biaya Transport Operasional Kantor & Rp. & 5.600 .000 \\
\hline Biaya Administrasi Kantor & Rp. & 5.366 .500 \\
\hline Biaya Usaha Lainnya & Rp. & 1.331 .500 \\
\hline Biaya Administrasi dan Operasional Amp Lainnya & Rp. & 27.177 .149 \\
\hline Biaya Penyusutan Peralatan Kantor & Rp. & 2.250 .000 \\
\hline Total Biaya Usaha & Rp. & 268.725 .149 \\
\hline Laba Bersih Usaha Sebelum Pajak & Rp. & 71.207.334 \\
\hline
\end{tabular}

Sumber: Laporan Laba Rugi PT Sinar Cipta Persada Sejati

Dari laporan laba rugi dapat dihitung pajak terutang pada PT. Sinar Cipta Persada Sejati adalah 25\% x Rp. $71.207 .334=$ Rp. 17.801.833. Pajak penghasilan badan yang harus di bayarkan oleh perusahaan adalah sebesar Rp. 17.801.833.

\subsection{Pembahasan}

Kebijakan perencanaan pajak. Dari laporan keuangan yang telah disajikan ada hal tertentu yang dapat dilakukan oleh perusahaan untuk meminimalisasi pajak penghasilan badan terutang yaitu: (1) berdasarkan Pasal 6 ayat 1 Undang-Undang Perpajakan No. 36 Tahun 2008 tentang Pajak Penghasilan yang dikeluarkan oleh PT. Sinar Cipta Persada Sejati dalam operasional perusahaan pada tahun 2018 mencakup: biaya gaji karyawan, biaya administrasi dan operasional; (2) biaya pendidikan karyawan dikeluarkan oleh PT. Sinar Cipta Persada Sejati untuk meningkatkan keahlian karyawannya untuk masa yang akan datang. Biaya ini merupakan biaya yang dapat dikurangkan dari penghasilan bruto (deductible expenses); dan (3) berdasarkan Keputusan Dirjen Pajak (KEP) No.220/PJ/2002 biaya pembelian telepon seluler dan pengisian pulsa terkait dengan jabatan dan pekerjaan dapat dijadikan sebagai beban fiskal atau beban yang dapat dikurangkan dari penghasilan bruto (deductable expenses) hanya sebesar $50 \%$ saja dari keseluruhan beban yang dikeluarkan. Jadi beban yang dikeluarkan berupa biaya pengisian pulsa terkait dengan jabatan dan pekerjaan kepada kepala pelaksana.

Laporan laba rugi setelah perencanaan pajak. Berdasarkan perhitungan pada penyajian Tabel 1 pajak penghasilan yang harus dibayar oleh PT. Sinar Cipta Persada Sejati apabila tidak melakukan pendidikan dan pengembangan SDM dan tidak melakukan pengisian pulsa adalah Rp. 17.801.833. 
Biaya Pendidikan dan Pengembangan SDM. Dengan perencanaan pajak perusahaan dapat penghematan pajak penghasilan badan yang harus dibayar oleh perusahaan yaitu sebesar Rp. 17.801.833 - Rp. 16.051.833 = Rp. 1.750.000.

Tabel 2. Laporan laba rugi dengan biaya pendidikan dan pengembangan SDM

\begin{tabular}{|c|c|c|}
\hline Uraian & Satuan (Rp) & Jumlah \\
\hline Pendapatan Jasa Proyek & Rp. & 3.341 .879 .914 \\
\hline \multicolumn{3}{|l|}{ Harga Pokok Proyek } \\
\hline Pembelian/Pemakaian Bahan dan Material & Rp. & 1.010 .322 .939 \\
\hline Upah Proyek & Rp. & 556.757 .968 \\
\hline Biaya Angkut Bahan/Material Proyek & Rp. & 98.441 .739 \\
\hline Biaya Operasional Proyek & Rp. & 114.265 .000 \\
\hline Biaya Penyusutan Peralatan Proyek & Rp. & 1.209 .659 .785 \\
\hline Biaya Proyek Lainnya & Rp. & 12.500 .000 \\
\hline Harga Pokok Proyek & Rp. & 3.001 .947 .431 \\
\hline Laba Kotor & Rp. & 339.932.483 \\
\hline \multicolumn{3}{|l|}{ Biaya Usaha } \\
\hline Biaya Gaji Karyawan Kantor & Rp. & 234.000 .000 \\
\hline Biaya Transport Operasional Kantor & Rp. & 5.600 .000 \\
\hline Biaya Administrasi Kantor & Rp. & 5.366 .500 \\
\hline Biaya Usaha Lainnya & Rp. & 1.331 .500 \\
\hline Biaya Administrasi dan Operasional Amp Lainnya & Rp. & 27.177.149 \\
\hline Biaya Penyusutan Peralatan Kantor & Rp. & 2.250 .000 \\
\hline Biaya Pendidikan dan Pelatihan SDM & Rp. & 7.000 .000 \\
\hline Total Biaya Usaha & Rp. & 275.725 .149 \\
\hline Laba Bersih Usaha Sebelum Pajak & Rp. & 64.207.334 \\
\hline
\end{tabular}

Sumber: Data Olahan

Biaya Pengisian Pulsa. Dengan menambahkan biaya pengisian pulsa perusahaan dapat penghematan pajak penghasilan badan yang harus dibayar oleh perusahaan yaitu sebesar Rp. 17.801.833 - Rp. 17.051.833 = Rp. 750.000 .

Tabel 3. Laporan laba rugi dengan biaya pengisian pulsa

\begin{tabular}{|c|c|c|}
\hline Uraian & Satuan (Rp) & Jumlah \\
\hline Pendapatan Jasa Proyek & Rp. & 3.341 .879 .914 \\
\hline \multicolumn{3}{|l|}{ Harga Pokok Proyek } \\
\hline Pembelian/Pemakaian Bahan dan Material & Rp. & 1.010 .322 .939 \\
\hline Upah Proyek & $\mathrm{Rp}$. & 556.757 .968 \\
\hline Biaya Angkut Bahan/Material Proyek & Rp. & 98.441 .739 \\
\hline Biaya Operasional Proyek & $\mathrm{Rp}$. & 114.265 .000 \\
\hline Biaya Penyusutan Peralatan Proyek & Rp. & 1.209 .659 .785 \\
\hline Biaya Proyek Lainnya & $\mathrm{Rp}$. & 12.500 .000 \\
\hline Harga Pokok Proyek & Rp. & 3.001 .947 .431 \\
\hline Laba Kotor & Rp. & 339.932.483 \\
\hline \multicolumn{3}{|l|}{ Biaya Usaha } \\
\hline Biaya Gaji Karyawan Kantor & Rp. & 234.000 .000 \\
\hline Biaya Transport Operasional Kantor & Rp. & 5.600 .000 \\
\hline Biaya Administrasi Kantor & Rp. & 5.366 .500 \\
\hline Biaya Usaha Lainnya & $\mathrm{Rp}$. & 1.331 .500 \\
\hline Biaya Administrasi dan Operasional Amp Lainnya & Rp. & 27.177.149 \\
\hline Biaya Penyusutan Peralatan Kantor & Rp. & 2.250 .000 \\
\hline Biaya Pengisian Pulsa & Rp. & 3.000 .000 \\
\hline Total Biaya Usaha & Rp. & 271.725 .149 \\
\hline Laba Bersih Usaha Sebelum Pajak & Rp. & 68.207.334 \\
\hline
\end{tabular}


Pajak Penghasilan yang dibayar setelah perencanaan pajak. Dari laporan laba rugi tabel 4 dapat dihitung pajak penghasilan terutang PT. Sinar Cipta Persada Sejati setelah dilaksanakan perencanaan pajak adalah $25 \%$ x Rp. 61.207.334 = Rp 15.301.833. Total pajak penghasilan yang harus dibayar oleh perusahaan yang dapat dilihat pada penyajian perhitungan pajak penghasilan badan terutang setelah kebijakan perencanaan pajak, PT. Sinar Cipta Persada Sejati dapat melakukan penghematan pajak sebesar Rp. 17.801 .833 - Rp 15.301.833 = Rp. 2.500.000.

Tabel 4. Laporan laba rugi setelah perencanaan pajak per 31 Desember 2017

\begin{tabular}{|c|c|c|}
\hline Uraian & Satuan (Rp) & Jumlah \\
\hline Pendapatan Jasa Proyek & $\mathrm{Rp}$. & 3.341 .879 .914 \\
\hline \multicolumn{3}{|l|}{ Harga Pokok Proyek } \\
\hline Pembelian/Pemakaian Bahan dan Material & Rp. & 1.010 .322 .939 \\
\hline Upah Proyek & Rp. & 556.757 .968 \\
\hline Biaya Angkut Bahan/Material Proyek & Rp. & 98.441 .739 \\
\hline Biaya Operasional Proyek & Rp. & 114.265 .000 \\
\hline Biaya Penyusutan Peralatan Proyek & Rp. & 1.209.659.785 \\
\hline Biaya Proyek Lainnya & Rp. & 12.500 .000 \\
\hline Harga Pokok Proyek & Rp. & 3.001 .947 .431 \\
\hline Laba Kotor & Rp. & 339.932.483 \\
\hline \multicolumn{3}{|l|}{ Biaya Usaha } \\
\hline Biaya Gaji Karyawan Kantor & Rp. & 234.000 .000 \\
\hline Biaya Transport Operasional Kantor & Rp. & 5.600 .000 \\
\hline Biaya Administrasi Kantor & Rp. & 5.366 .500 \\
\hline Biaya Usaha Lainnya & Rp. & 1.331 .500 \\
\hline Biaya Administrasi dan Operasional Amp Lainnya & Rp. & 27.177.149 \\
\hline Biaya Penyusutan Peralatan Kantor & Rp. & 2.250 .000 \\
\hline Biaya Pengisian Pulsa & Rp. & 3.000 .000 \\
\hline Total Biaya Usaha & Rp. & 271.725 .149 \\
\hline Laba Bersih Usaha Sebelum Pajak & Rp. & 68.207.334 \\
\hline
\end{tabular}

Sumber: Data Olahan

\section{KESIMPULAN DAN SARAN}

\subsection{Kesimpulan}

Berdasarkan hasil penelitian dan pembahasan mengenai analisis perencanaan pajak dalam kaitannya untuk meminimalisir perhitungan pajak penghasilan badan terutang pada PT. Sinar Cipta Persada Sejati maka penulis membuat kesimpulan yaitu:

1. Penerapan perencanaan pajak pada PT. Sinar Cipta Persada Sejati, telah didukung oleh sistem administrasi yang tertib, rapi dan teratur sehingga dapat berjalan lancar sesuai dengan rencana untuk meminimalisir perhitungan pajak penghasilan badan guna mendukung strategi perusahaan secara keseluruhan dalam rangka meningkatkan kinerja.

2. Perencanaan pajak bagi pajak penghasilan badan, setidak - tidaknya harus memenuhi berbagai ketentuan dan persyaratan yang berkaitan dengan perhitungan penghasilan kena pajak. Hal ini mencakup begitu banyak pos dan perlakuan perpajakan, yang diatur juga dengan sekian banyak ketentuan perpajakan. Oleh karena itu, perlu diberikan pengelompokan yang sifatnya fleksibel dan cukup akurat, untuk membedakan berbagai cara atau pendekatan yang bisa memungkinkan tercapainya efisiensi Pajak Penghasilan Badan.

\subsection{Saran}

Dari hasil analisis dan kesimpulan, penulis memberikan saran yang dapat bermanfaat bagi PT. Sinar Cipta Persada Sejati, yaitu:

1. Agar supaya kebijakan perencanaan pajak pada PT. Sinar Cipta Persada Sejati dilaksanakan dengan tepat karena dengan adanya perencanaan pajak maka akan 
memperoleh keuntungan bagi perusahaan yaitu adanya penghematan pajak, khususnya pajak penghasilan badan yang terhutang dan peningkatan laba bersih perusahaan.

2. Perusahaan harus lebih memahami ketentuan peraturan perpajakan yang berlaku terutama pajak penghasilan yang diatur dalam Undang-Undang Pajak Penghasilan No. 36 Tahun 2008, serta harus selalu mengikuti perkembangan perubahan peraturan perpajakan.

\section{DAFTAR PUSTAKA}

Bahri, S. (2016). Pengantar Akuntansi. Yogyakarta: Penerbit Andi.

Cynthia, G. C. (2017). Tax planning PPh Badan untuk meminimalkan pajak penghasilan terutang (Studi kasus PT XYZ. Skripsi. Universitas Katolik Parahyangan, Bandung. http://repository.unpar.ac.id/handle/123456789/3569.

Efendi, I. (2014). Analisis Pengaruh Perencanaan Pajak (Tax Planning) Sebagai Upaya Menekan Beban Pajak Penghasilan Perusahaan Terhadap Ekuitas Pada Perusahaan Perbankan Yang Terdaftar Di Bursa Efek Indonesia Tahun 2011-2012. Skripsi. Universitas Muhammadiyah, Surakarta. http://eprints.ums.ac.id/29276/.

Estralita. (2014). Pengertian Akuntansi Fungsi Pajak. Jakarta: Penerbit Adriani.

Ga, D. R. (2017). Akuntansi Dasar : Teori dan Praktik. Yogyakarta: Penerbit Andi.

Gunadi. (2013). Panduan Komprehensif Pajak Penghasilan Edisi 2013. Jakarta: Penerbit Bee Media.

Kawor, S., \& Kportorgbi, H. (2014). Effect of tax planning on firms market performance: Evidence from Listed Firms in Ghana. International Journal of Economics and Finance, 6(3), 162-168. https://doi.org/10.5539/ijef.v6n3p162.

Keputusan Direktur Jenderal Pajak Nomor KEP-220/PJ./2002 Tentang Perlakuan Pajak Penghasilan Atas Biaya Pemakaian Telepon Seluler Dan Kendaraan Perusahaan, Jakarta.

Mardiasmo. (2016). Perpajakan. Edisi Revisi. Yogyakarta: Penerbit Andi.

Pohan, C. A. (2013). Manajemen Perpajakan : Strategi Perencanaan Pajak dan Bisnis, Edisi Revisi. Jakarta: PT. Gramedia Pustaka Utama.

Resmi, S. (2014). Perpajakan Teori dan Kasus, Edisi 8 Buku 1. Jakarta: Salemba Empat.

Setyaningrum, C. D., \& Suryarini, T. (2016). Analysis of corporate income tax reduction a study case on manufacturing companies in Indonesia in the year 2008-2014. Jurnal Dinamika Akuntansi, 8(1), 14-22. https://doi.org/10.15294/jda.v8i1.9115

Sitohang, R. C. (2017). Analisis Penerapan Perencanaan Pajak (Tax Planning) PPh Pasal 21 Dalam Upaya Efisiensi Beban Pajak Penghasilan Badan Usaha (Studi Kasus Pada PT. XYZ). Universitas Lampung. Skripsi. http://digilib.unila.ac.id/28839/. 09 Maret 2019.

Undang-Undang No.36 Tahun 2008 mengenai Perubahan Keempat atas Undang-Undang No. 17 Tahun 2000 tentang Pajak Penghasilan, Jakarta.

Undang-Undang No.28 Tahun 2007 mengenai Perubahan Ketiga atas Undang-Undang No. 16 Tahun 2000 Tentang Ketentuan Umum dan Tata Cara Perpajakan, Jakarta. 